\title{
Self-Reported Cognitive Decline on the Informant Questionnaire on Cognitive Decline in the Elderly Is Associated with Dementia, Instrumental Activities of Daily Living and Depression but Not Longitudinal Cognitive Change
}

\author{
Ranmalee Eramudugolla ${ }^{a} \quad$ Nicolas Cherbuin $^{a}$ Simon Easteal ${ }^{b}$ \\ Anthony F. Jorm ${ }^{c}$ Kaarin J. Anstey ${ }^{\mathrm{a}}$ \\ ${ }^{a}$ Centre for Research on Ageing, Health and Wellbeing, ${ }^{b}$ John Curtin School of Medical Research, \\ Australian National University, Canberra, A.C.T., and ' ${ }^{\mathrm{C}}$ Centre for Youth Mental Health, University of Melbourne, \\ Melbourne, Vic., Australia
}

\section{Key Words}

Aging $\cdot$ Cognition $\cdot$ Cognitive complaints $\cdot$ Cognitive decline $\cdot$ Epidemiology $\cdot$ Prospective study

\begin{abstract}
Background/Aim: A subjective history of cognitive decline is integral to dementia screening, yet there are few data on the accuracy of retrospective self-reports. We prospectively examined the longitudinal predictors of self-reported decline, including rate of cognitive change, clinical diagnosis, depressive symptoms and personality. Methods: We used a large ( $\mathrm{n}=$ $2,551)$ community-dwelling sample of older adults (60-64 years at baseline) and tracked their cognitive functioning over 3 waves across a period of 8 years. Individual rates of change in multiple domains of cognition, incident dementia and mild
\end{abstract}

cognitive disorders, apolipoprotein E (APOE) \&4 genotype, level of education, depressive symptoms and personality were examined as predictors of wave 3 retrospective self-reported decline as measured by the Informant Questionnaire on Cognitive Decline in the Elderly. Results: The rate of cognitive decline did not predict subjective decline. Significant predictors of self-reported decline included dementia diagnosis, problems with instrumental activities of daily living, depression and neuroticism at the time of self-report, as well as the presence of an APOE \&4 allele. Conclusions: In this relatively young cohort, retrospective self-report of cognitive decline does not reflect objective deterioration in cognition over the time period in question, but it may identify individuals in the initial stages of dementia and those with elevated psychological and genotypic risk factors for the development of dementia.

Copyright @ 2012 S. Karger AG, Basel

\section{KARGER \\ Fax +4161306 1234}

E-Mail karger@karger.ch

www.karger.com
(C) 2012 S. Karger AG, Basel

$1420-8008 / 12 / 0346-0282 \$ 38.00 / 0$

Accessible online at:

www.karger.com/dem
Ranmalee Eramudugolla

Centre for Research on Ageing, Health and Wellbeing

Australian National University

Canberra, ACT 0200 (Australia)

E-Mail ranmalee.eramudugolla@anu.edu.au 


\section{Introduction}

The diagnostic utility of subjective cognitive difficulties is contentious [1-4], particularly as measures of selfreported cognitive impairment are correlated with depression, anxiety and personality $[1,3,5,6]$. Furthermore, self-reported cognitive ability can be inaccurate in healthy controls as well as in subjects with mild cognitive impairment (MCI) and dementia [2, 7]. To date, findings regarding the predictive validity of subjective complaints have been mixed, partly due to differences in methodology and the quality of instruments used. Several prospective cohort studies of healthy elderly report that memory concerns predict dementia independent of depression [8-11]. Although positive, these studies have typically used rough self-report measures (e.g. a single yes/no question such as 'Do you have problems with your memory?') and basic screens for baseline cognitive function and have not examined the trajectory of decline leading up to the subjective report. Indeed, studies that have used a structured self-report measure and detailed cognitive testing report that subjective concerns are not predictive of cognitive change $[4,12,13]$, particularly after controlling for anxiety and depression [4].

Individuals may be more sensitive to change in cognitive function over time, rather than impairment at a given time point [13-15]. Certainly, self-reported deficits appear to have poor validity in relation to current cognitive status [3, 5, 16-18]. Studies that have examined cognitive change as a predictor of retrospective self-report have generally tracked change over 3-4 years across a single interval $[4,12-15,19]$. Several have also excluded individuals with diagnoses $[12,13,19]$, making it difficult to evaluate the diagnostic significance of retrospective concerns of decline. Two studies reported significant associations between objective cognitive decline and subjective reports but failed to control for depression and personality [14] and used a self-report scale that questioned participants on memory and attention difficulties over the past month, which is likely more sensitive to depressive symptoms than progressive cognitive decline [15].

A commonly used measure of informant concerns regarding change in cognitive function is the Informant Questionnaire on Cognitive Decline in the Elderly (IQCODE). It is widely used in clinical and research settings and has well-defined psychometric properties [20-22]. Informant reports using the IQCODE are unaffected by patient level of education and have a similar sensitivity to cognitive impairment as do traditional screening measures like the Mini-Mental State Examination (MMSE)
[22-24]. The questionnaire measures the degree of perceived cognitive change (either improvement or decline) over the preceding 10 years, using a 5-point scale and questions regarding functional memory, learning and problem solving. Although the IQCODE was designed as an informant questionnaire, there is interest in using it as a self-report measure [12, 25]. A psychometric evaluation of the IQCODE as a self-report measure (IQCODE-SR) found that it had modest correlation with current cognitive function, was feasible in a general practitioner-referred sample and met the basic requirements of a good measurement [25]. This was critiqued in a subsequent study that found no correlation between IQCODE-SR and cognitive change scores over 3 years in a sample of healthy older women [12]. In the present study, we examined the predictors of retrospective self-reported decline using the IQCODE-SR in a large representative community-based sample. We hypothesised that (1) decline on the IQCODE-SR may reflect longitudinal cognitive change when measured over a similar time frame to selfreport and that (2) clinically significant predictors of IQCODE-SR may be identified using a more representative sample and a wider range of predictors than in prior studies $[12,19,25]$. In addition to longitudinal cognitive change, predictors in the model included incident diagnosis of dementia and mild cognitive disorders, depression, change in depression, neuroticism, complex instrumental activities of daily living (IADLs) and apolipoprotein E (APOE) \&4 genotype. The latter was included because of its role in Alzheimer's disease and the paucity of data on the relationship between dementia biomarkers and self-report measures.

\section{Methods}

\section{Participant Selection and Recruitment}

The data were collected as part of the Personality and Total Health Through Life (PATH) longitudinal cohort study initiated in 1999, for which 3 cohorts (initially aged 20-24, 40-44 and 6064 years) have been interviewed and assessed at 4 -yearly intervals on a range of psychological, cognitive and health-related factors. The design of the PATH study has been described in detail elsewhere [26]. The present study focuses on the cohort initially aged 60-64 years over the first 3 waves of data collection in 2001 (wave 1), 2005 (wave 2) and 2009 (wave 3). The sample was randomly drawn from the electoral roll of residents of the city of Canberra and the neighbouring town of Queanbeyan in Australia (voting is compulsory for Australian citizens). The cohort initially included 2,551 subjects (fig. 1). The study was approved by the Australian National University ethics panel. After a complete description of the study to the participants, written informed consent was obtained. 


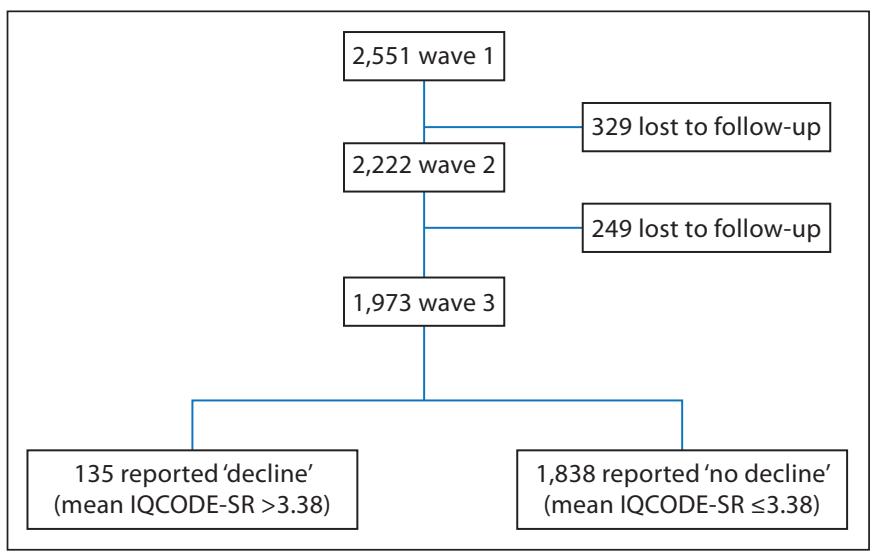

Fig. 1. Flow chart illustrating progress of the sample through PATH data collection from wave $1(2000 / 2001)$ to wave 2 (2004/2005) to wave $3(2008 / 2009)$.

Cognitive Change and Measures of Depressive Symptoms and Personality

After providing written consent, participants took part in a structured interview that included a main questionnaire completed using a hand-held computer and cognitive tests that were administered by a trained interviewer. This included the following tests of attention, auditory-verbal immediate and delayed recall, verbal working memory, processing speed and verbal ability/vocabulary: MMSE [27], immediate and delayed recall of the California Verbal Learning Test [28], Spot-the-Word test [29], Symbol Digit Modalities Test [30] and Digit Span Backwards [31]. In addition, the Patient Health Questionnaire-9 (PHQ-9) [32] was administered as part of the main survey in each wave. To control for the influence of personality on self-report (specifically neuroticism [3]), we used the neuroticism measure (termed 'emotional stability') from the Big Five 10-Item Personality Inventory [33] administered in wave 3. Scores on the emotional stability scale were reflected and called 'neuroticism' to preserve the traditional conceptualisation of this domain and to facilitate interpretation of correlations. A self-report inventory of problems completing IADLs was also completed in wave 3 . The IADL variable used in the analyses was a composite measure representing either difficulty or inability performing any of the following IADLs: map reading, meal preparation, grocery shopping, making phone calls and taking medication.

Individual longitudinal trajectories of cognitive change were computed based on linear mixed effects (LME) models for each cognitive measure over time (in years). The LME models were performed on the full wave 3 sample $(n=1,973)$. Longitudinal change in depressive symptoms was similarly computed using an LME model for PHQ-9 depression total scores over time. Table 1 presents the mean slopes over time for each of the cognitive and mood predictors.

\section{Diagnosis of Mild Cognitive Disorders and Dementia}

Diagnosis of MCI, other preclinical dementia syndromes and dementia occurred through a 2 -stage process using research diagnostic criteria. Participants scoring below specified cut-offs on
§ the cognitive tests described above were referred for an intensive clinical assessment, medical testing, full neuropsychological and neurological assessment and consensus diagnoses by experienced clinicians after ruling out secondary causes of MCI (e.g. medical, neurological and depression/anxiety). Diagnostic criteria applied included MCI [34], age-associated cognitive decline [35], age-associated memory impairment [36], DSM-IV mild neurocognitive 응 disorder [37], DSM-IV other cognitive disorder [37] and Clinical Dementia Rating $\geq 0.5$ [38]. Participants receiving any diagnosis of MCI, age-associated cognitive decline, age-associated memory impairment, mild neurocognitive disorder or Clinical Dementia Rating $>0.5$ were grouped in a single category called 'mild cognitive disorders'. Thus, the diagnosis variable consisted of undiagnosed, mild cognitive disorders and dementia.

\section{Self-Reported Decline}

The IQCODE (Short Version) was administered during the third wave of data collection to obtain a subjective measure of cognitive change over the preceding 10 years. The use of the short version of the IQCODE is advocated based on time efficiency as well as its psychometric properties [22]. The short IQCODE is composed of 16 interview questions assessing changes in everyday memory function and problem solving, where the respondent is asked to rate the magnitude of change over the previous 10 years using a 5-point scale ranging from 1 ('much improved') to 5 ('much worse'), with 3 indicating 'no change'. The IQCODE-SR was developed using the short-form informant IQCODE and consists of the same set of questions [25]. Summary scores were obtained by calculating the average score for the 16 items [22]. Mean IQCODE scores lower than 3.3-3.6 for community samples and 3.4-4.0 for clinical samples reflect perceived improvements in cognition, and scores above these cut-offs reflect perceived worsening of cognition. Thus, an inverse relationship is expected between cognitive scores and the mean IQCODE-SR, such that low scores on the cognitive measures are associated with high scores (i.e. worsening ability) on the IQCODE-SR. Similarly, an inverse relationship is expected between the slope of cognitive change and the mean self-reported IQCODE scores.

As a screening tool, the IQCODE is typically used with a cutoff to detect patients likely to show dementia [20,25]. Because we were interested in the utility of self-reported decline for detecting individuals with objective decline, we dichotomised the IQCODE-SR using a cut-off of 3.38 to categorise participants into those reporting decline (scores $>3.38$ ) and those not reporting decline (scores $\leq 3.38$ ). This cut-off was based on other Australian epidemiological studies using the informant report IQCODE with individuals aged 70 years and over [22] and a similar target population to the present work [20]. The chosen cut-off had a reported sensitivity of 0.79 and specificity of 0.82 for detecting dementia.

\section{APOE Genotyping}

Genomic DNA was extracted from buccal swabs using QIAGEN DNA Blood kits (No. 51162, QIAGEN, Hilden, Germany). Two single-nucleotide polymorphisms ( $r$ s29358 and rs7412) were genotyped to identify APOE genotypes comprising the APOE $\varepsilon 2$, $\varepsilon 3$ and $\varepsilon 4$ alleles using TaqMan assays (Applied Biosystems, Foster City, Calif., USA) as described elsewhere [39]. The $\varepsilon 2$ and $\varepsilon 3$ alleles were combined in this analysis to give the following 3 composite genotypes: $\varepsilon 4-/ \varepsilon 4-, \varepsilon 4-/ \varepsilon 4+$ and $\varepsilon 4+/ \varepsilon 4+$. 
Table 1. Demographic, cognitive and psychological characteristics of the sample $(n=1,973)$

\begin{tabular}{|c|c|c|c|c|c|}
\hline & $\begin{array}{l}\text { Decline } \\
(\mathrm{n}=135)\end{array}$ & $\begin{array}{l}\text { No decline } \\
(\mathrm{n}=1,838)\end{array}$ & $\mathrm{p}$ & $\begin{array}{l}\text { All } \\
(\mathrm{n}=1,973)\end{array}$ & $\begin{array}{l}95 \% \text { CI for } \\
\text { slopes }\end{array}$ \\
\hline Males, $\mathrm{n}$ & $88(65.4)$ & $931(50.7)$ & $<0.001$ & & \\
\hline Age at wave 3 , years & 70.75 & 70.59 & 0.26 & 70.60 & \\
\hline Years of education & 13.99 & 13.98 & 0.97 & 13.98 & \\
\hline Diagnostic status at wave $3, \mathrm{n}$ & & & $<0.001$ & & \\
\hline Dementia & $3(2)$ & $5(0.2)$ & & & \\
\hline Self-reported IADL problems ${ }^{\mathrm{a}}$ at wave 3 & $43(32)$ & $257(14)$ & $<0.001$ & & \\
\hline FFM neuroticism ${ }^{b}$ at wave 3 & 2.63 & 2.36 & & 2.37 & \\
\hline PHQ-9 depression category at wave $3, \mathrm{n}$ & & & $<0.001$ & & \\
\hline No depression & $96(71)$ & $1,692(92)$ & & & \\
\hline Sub-syndromal depression & $18(13.5)$ & $84(4.6)$ & & & \\
\hline Immediate recall & -0.089 & -0.083 & 0.19 & $-0.083 * *$ & -0.09 to -0.07 \\
\hline Delayed recall decline & -0.051 & -0.054 & 0.58 & $-0.054 * *$ & -0.07 to -0.04 \\
\hline Working memory & -0.004 & -0.004 & 0.99 & -0.004 & -0.014 to 0.01 \\
\hline Processing speed & -0.429 & -0.390 & 0.004 & $-0.39 * *$ & -0.43 to -0.36 \\
\hline Verbal ability & 0.088 & 0.084 & 0.29 & $0.085^{* *}$ & 0.07 to 0.10 \\
\hline PHQ-9 depression score & 0.035 & 0.014 & 0.002 & 0.015 & -0.01 to 0.03 \\
\hline APOE $\varepsilon 4$ status ${ }^{\mathrm{c}}, \mathrm{n}$ & & & 0.004 & & \\
\hline$\varepsilon 4-$ & $84(62)$ & $1,358(74)$ & & & \\
\hline$\varepsilon 4+$ & $51(38)$ & $480(26)$ & & & \\
\hline IQCODE-SR mean score at wave 3 & 3.57 & 2.95 & & & \\
\hline
\end{tabular}

Results represent pooled estimates from 5 imputed datasets. Figures in parentheses represent percentages. ${ }^{* *} \mathrm{p}<0.01 . \mathrm{MCD}=\mathrm{Mild}$ cognitive disorder; FFM = Five Factor Model.

a Either difficulty or inability performing any of the following IADLs: map reading, meal preparation, grocery shopping, making phone calls, taking medication.

${ }^{\mathrm{b}}$ Reflected emotional stability scale from the Big Five 10-Item Personality Inventory (square root transformed).

${ }^{c}$ Genotype distribution was in Hardy-Weinberg equilibrium for those reporting decline $\left(\chi^{2}<1.0\right)$ and no decline $\left(\chi^{2}=1.43\right.$, $\mathrm{p}>$ 0.05).

Statistical Analyses IBM).

All analyses were conducted using PASW Statistics 18 (SPSS,

\section{Missing Data and Multiple Imputation}

Of the 1,973 participants followed up in wave 3 , the IQCODESR was missing or incomplete for 332, and 331 of these participants also had missing data on the neuroticism measure. APOE $\varepsilon 4$ genotype was missing for a further 100 participants. In all, $24.6 \%$ of cases had missing data, representing $3.03 \%$ of all values in the dataset. A missing value analysis using Expectation Maximization (EM) indicated that the data for IQCODE-SR were not missing completely at random (Little's missing completely at random test: $\chi^{2}=248.26, \mathrm{p}<0.001$ ). A multiple imputation (MI) approach was used instead to impute all missing data, producing 5 imputed datasets with 10 iterations. Prior to MI, skewness was corrected with a square root transform for the neuroticism measure and the use of depression severity categories for the wave 3 PHQ-9 depression measure. Variables for the main logistic regression analysis represented a subset of the predictors for MI.

\section{Logistic Regression}

To examine predictors of self-reported decline on the IQCODE-SR, we used binomial logistic regression with IQCODESR category as the dependent variable and the 6 cognitive slopes as predictors. The model also included dementia diagnostic categories in wave 3 , depression category in wave 3 and longitudinal change in depression, self-reported IADL problems, APOE $\varepsilon 4$ genotype, neuroticism and years of education. Results for the pooled imputed dataset are shown in table 2 . 
Table 2. Logistic regression of model with all predictors of interest

\begin{tabular}{|c|c|c|c|c|c|}
\hline Predictor & $\beta$ & $\operatorname{SE} \beta$ & $\mathrm{p}$ & OR & $95 \% \mathrm{CI}$ \\
\hline \multicolumn{6}{|l|}{ Slopes of cognition and mood } \\
\hline MMSE & 0.561 & 3.38 & 0.871 & 1.75 & $0.001-2,646.3$ \\
\hline Immediate recall & -3.73 & 3.32 & 0.269 & 0.024 & $0.0-20.2$ \\
\hline Delayed recall & 4.10 & 3.31 & 0.229 & 60.04 & $0.06-5672$ \\
\hline Working memory & 0.381 & 2.48 & 0.878 & 1.46 & $0.01-197.9$ \\
\hline Processing speed & -0.649 & 0.862 & 0.456 & 0.523 & $0.091-2.99$ \\
\hline Verbal ability & 1.83 & 2.88 & 0.527 & 6.22 & $0.021-1,871.5$ \\
\hline APOE $\varepsilon 4$ ( $\varepsilon 4-$ vs. $\varepsilon 4+)$ & 0.510 & 0.230 & $0.030 *$ & 1.67 & $1.05-2.64$ \\
\hline Years of education & 0.068 & 0.044 & 0.127 & 1.07 & $0.98-1.17$ \\
\hline \multicolumn{6}{|l|}{ Diagnostic category } \\
\hline MCD & 0.878 & 0.480 & 0.083 & 2.41 & $0.882-6.57$ \\
\hline Dementia & 2.03 & 0.932 & $0.031 *$ & 7.62 & $1.21-48.14$ \\
\hline \multicolumn{6}{|l|}{ Depression category } \\
\hline Sub-syndromal & 0.914 & 0.381 & $0.022 *$ & 2.49 & $1.15-5.40$ \\
\hline Minor & 0.700 & 0.458 & 0.131 & 2.01 & $0.81-5.02$ \\
\hline Major & 2.41 & 0.652 & $<0.001^{* *}$ & 11.13 & $3.06-40.5$ \\
\hline Slope of depression & -0.313 & 1.56 & 0.842 & 0.731 & $0.03-16.40$ \\
\hline Neuroticism $^{\mathrm{a}}$ & 0.675 & 0.226 & $0.005^{*}$ & 1.96 & $1.24-3.10$ \\
\hline IADL problems ${ }^{\mathrm{b}}$ & 0.750 & 0.233 & $0.002 * *$ & 2.12 & $1.34-3.35$ \\
\hline Constant & -6.33 & 1.03 & $<0.001 * *$ & 0.002 & $0.0-0.014$ \\
\hline Tests & $\chi^{2}$ & & d.f. & $\mathrm{p}$ & \\
\hline \multicolumn{6}{|l|}{ Overall model evaluation } \\
\hline Likelihood ratio test & \multicolumn{2}{|c|}{$106.4-123.38^{c}$} & 16 & \multicolumn{2}{|l|}{$<0.001 * *$} \\
\hline \multicolumn{6}{|l|}{ Goodness-of-fit test } \\
\hline Hosmer and Lemeshow & \multicolumn{2}{|c|}{$6.71-9.79^{c}$} & 8 & \multicolumn{2}{|l|}{$>0.05$} \\
\hline
\end{tabular}

Results represent pooled estimates from 5 imputed datasets. * $\mathrm{p}<0.05 ; * * \mathrm{p}<0.01$. MCD $=$ Mild cognitive disorder; d.f. = degrees of freedom.

${ }^{a}$ Reflected emotional stability scale from the Big Five 10-Item Personality Inventory, square root transformed for MI.

b Either difficulty or inability performing any of the following IADLs: map reading, meal preparation, grocery shopping, making phone calls, taking medication.

${ }^{c}$ Results of $\chi^{2}$ tests show range of values obtained for the 5 imputed datasets.

\section{Results}

\section{Descriptives}

As a group, participants' scores on all cognitive measures declined over time, except for verbal ability (Spotthe-Word task) and working memory (Digits Backward; table 2). Separate LME models of each cognitive measure over time indicated significant longitudinal decline on the MMSE of 0.02 points per year $(\mathrm{t}=5.81, \mathrm{p}<0.001)$, decline on immediate recall by 0.08 words per year $(t=$ $13.31, \mathrm{p}<0.001)$, decline on delayed recall by 0.05 words per year $(\mathrm{t}=8.23, \mathrm{p}<0.001)$ and decline on processing speed (Symbol Digit Modalities Test) by 0.39 items per year $(\mathrm{t}=22.15, \mathrm{p}<0.001)$. Performance on verbal ability increased significantly by 0.08 items a year $(t=10.76, \mathrm{p}<$ 0.001 ), and performance on working memory was stable across time $(t=0.76, p>0.10)$. These rates of decline are comparable to those reported in other studies on cognitive change in non-clinical young-old cohorts [40,41]. Depressive symptoms as measured by the PHQ- 9 did not change over the 3 waves (parameter estimate $=0.015 ; \mathrm{t}=$ $1.77, \mathrm{p}=0.078$ ).

Although follow-up rates at each wave were high $(88 \%$ at wave 3 and $87 \%$ at wave 2) [26], all participants lost to 
follow-up over the course of the study $(\mathrm{n}=578)$ had fewer years of education [mean (SD): 13.21 (3.0) vs. 13.98 (2.7) years] and poorer performance on all cognitive measures at baseline relative to those retained at wave 3 (online suppl. table 1, www.karger.com/doi/10.1159/000345439). Those lost to follow-up were also more depressed at baseline [mean (SD) PHQ-9 total score: 3.2 (4.2) vs. 2.3 (3.0); $\mathrm{p}<0.001]$. There were no differences in subjective memory problems ( 23.1 vs. $23.8 \%$ ) or rate of functional interference from such memory problems (15.8 vs. $12.5 \%)$; however, more of those lost to follow-up reported consulting a doctor about subjective memory problems at baseline (32.6 vs. $19.5 \%$; $\mathrm{p}<0.05$ ). There were no differences in gender or APOE $\varepsilon 4$ genotype distribution (online suppl. table 1).

\section{Logistic Regression Analysis}

Results of logistic regression analysis of the pooled, imputed datasets are presented in table 2. This model significantly predicted self-reported decline [range of model $\chi^{2}$ (16 degrees of freedom) for 5 imputed datasets: 106.4-123.38; all $\mathrm{p}<0.001]$, and the inferential goodness-of-fit test (Hosmer and Lemeshow) yielded $\chi^{2}$ values (8 degrees of freedom) ranging from 6.71 to 9.79 , all of which were non-significant $(p>0.10)$, indicating good model fit to the datasets. Within the model, none of the cognitive change predictors were significantly associated with self-reported decline after controlling for the psychological and genotype predictors. This was the case even when diagnostic category was excluded from the analysis. The slope of depression also did not contribute to the model ( $p>0.05)$, and this did not change if wave 3 depression was omitted as a predictor $(p=0.09)$. Years of education did not predict self-reported cognitive decline $(\mathrm{p}>0.05)$.

Depression category at wave 3 was a significant predictor of self-reported decline. Here, sub-syndromal depressive symptoms increased the odds of reporting decline by a factor of 2.49 [95\% confidence interval (CI) 1.15-5.4; p $<0.05$ ], and major depressive symptoms increased the odds of reporting decline by a factor of 11.13 (95\% CI 3.06-40.54; $\mathrm{p}<0.001)$. Minor depressive symptoms did not predict self-reported cognitive decline $(\mathrm{p}>0.05)$. Neuroticism at wave 3 also significantly predicted selfreported decline $(\mathrm{p}=0.005)$ such that for every point increase in neuroticism, the odds of reporting decline increased by a factor of 1.96 (95\% CI 1.24-3.10).

Relative to no diagnosis, a diagnosis of dementia at wave 3 significantly predicted self-reported decline [odds ratio (OR) 7.62, 95\% CI 1.21-48.14; $\mathrm{p}<0.05$ ]; however, a diagnosis of mild cognitive disorder did not ( $p>0.05)$. Self-reported IADL difficulties predicted self-reported cognitive decline (OR 2.12, 95\% CI 1.34-3.35; p < 0.01), as did APOE $\varepsilon 4$ genotype $(\mathrm{p}<0.05)$. With the latter predictor, the presence of the $\varepsilon 4$ allele increased the odds of reporting decline by a factor of 1.67 (95\% CI 1.05-2.64).

Thus, for the present sample of 70 -year-old community-based individuals, self-reported decline on the IQCODE-SR was not predicted by objective changes in cognition over the preceding 8 years. Significant predictors of self-reported decline included dementia diagnosis, depression and neuroticism at the time of self-report, selfreported IADL difficulties and also the presence of the APOE $\varepsilon 4$ allele.

\section{Discussion}

We investigated cognitive and psychological predictors of retrospective self-reported changes in everyday cognitive function in a community-based sample of 1,973 individuals aged in their early 70 s. The results revealed that although there was a gradual and significant decline in several cognitive measures over the 8-year period (table 1), participants' self-reported level of decline was not predicted by these trajectories. Predictors of self-reported decline included incident dementia and self-reported problems with complex IADLs, as well as depression and neuroticism at the time of self-report. Our findings provide further insight into subjective cognitive concerns and have important implications for the use of the IQCODE-SR as a screening measure.

Although the cohort as a whole demonstrated a statistically significant but subtle decline in episodic memory, attention and speed of information processing, these trajectories did not predict self-reported decline. The results are in keeping with previous cross-sectional studies $[3,5$, 16-18] and studies examining longitudinal cognitive change as a predictor of subjective reports $[4,12-14,19]$. Possible explanations for the lack of a relationship between cognitive change and subjective decline in our study are that overall cognitive decline was small relative to previous reports and only a minority reported decline on the IQCODE. Most previous studies have used older cohorts with a broader age range $[4,13,19]$ or clinicbased samples [25], which may account for the greater decline in those samples. Also, the small number of participants reporting decline in our study may reflect the fact that testing and recruitment occurred in the context of a broader epidemiological study and was therefore less 
likely to bias subjective perceptions of decline when compared to clinic-based recruitment [25] or self-report after memory testing [13]. Nevertheless, our results confirm and extend the current understanding that cognitive decline over time as measured by standard neuropsychological tests is unrelated to subjective perceptions of cognitive decline.

The IQCODE primarily asks participants about decline in everyday memory, learning and problem solving and as such focuses the participant on everyday function and disability rather than impairment. Accordingly, we found that participants reporting problems with complex IADLs were 2.12 (95\% CI 1.34-3.35) times more likely to also report cognitive decline on the IQCODE-SR, further supporting this group's subjective experience of functional difficulties despite cognitive trajectories that are similar to those reporting no decline. This finding is in keeping with other studies that have included measures of self-reported activity levels [12].

We found that clinical diagnosis at wave 3 significantly predicted self-reported decline. Participants diagnosed with dementia were 7.62 (95\% CI 1.21-48.14) times more likely to report cognitive decline on the IQCODE-SR. This relationship was not apparent for mild cognitive disorders. These results are consistent with prior reports [19, 42] and suggest that the IQCODE-SR may be able to detect a group of individuals in the initial stages of dementia who already experience its impact on everyday function (as measured by the IQCODE-SR) and have sufficient insight to make accurate self-reports.

Our finding that individuals with greater depressive symptoms and higher neuroticism are more likely to report decline is also well supported in the literature [1,3-6, $12,13]$. In our sample, depressive symptoms did not increase appreciably over the course of the 8 years, and longitudinal change in depression was unrelated to subjective decline. However, those reporting decline showed a sharp increase in depression at wave 3 (fig. $2 \mathrm{~g}$ ), and the strongest predictor of self-reported decline was the presence of major depressive symptoms, with these participants being 11.13 (95\% CI 3.06-40.5) times more likely to report decline on the IQCODE-SR. Individuals with less severe depressive symptoms that fell short of either minor or major depression were also more likely to report cognitive decline, but to a lesser degree (OR 2.49, 95\% CI 1.155.40). It is not clear why a similar relationship was not found for minor depressive symptoms. Nevertheless, subsyndromal depressive symptoms are reported by 30 $50 \%$ of those with MCI [43], and both major depression and subsyndromal depression have been considered pro- dromal features of incipient dementia [44]. These results suggest that even in the absence of measurable cognitive impairment, individuals reporting a decline represent a group that may already be exhibiting preclinical features of decline such as depressive symptoms and/or self-reported IADL difficulties.

Few studies have considered biomarkers of dementia as predictors of self-reported decline. Here, we included APOE $\varepsilon 4$ genotype in the model and found that carriers of the $\varepsilon 4$ allele were somewhat more likely to report decline (OR 1.67, 95\% CI 1.05-2.64) than were non-carriers. Interestingly, this relationship was apparent after accounting for diagnostic status. Several previous reports have found an association between APOE $\varepsilon 4$ genotype and subjective memory concerns, but only in the context of objective memory impairment or decline [45-48]. Although we did not ask about prior knowledge of dementia risk factors at the time of assessment, none of the participants had requested genotype data from the study coordinators at the time of self-report.

Limitations of the study include the fact that although sample attrition was generally low, those not followed up at wave 3 were significantly less educated, had lower baseline cognitive performance and higher baseline depression and were more likely to have sought medical advice about memory problems at baseline. Strengths of the study include the use of a well-validated instrument for the assessment of subjective cognitive change and the accrual of cognitive data across 3 waves, spanning a time period that complements our retrospective measure. Also, our sample was an unselected community-based cohort with rates of conversion to MCI and dementia that are representative of other population estimates (Anstey et al. [49]).

The IQCODE is primarily used as an informant questionnaire, but our data together with previous work [12, 25] suggest that it can be used as a self-report tool, at least in community-based populations of the young-old. Our results support and extend previous findings and show that although measures of self-reported decline cannot be used as a proxy for cognitive assessment, they can be sensitive to dementia diagnosis after accounting for depression, personality and IADL factors, which are also significant predictors of self-reported decline. Furthermore, self-reported decline on the IQCODE-SR may be more frequent in those with elevated psychological and genotypic risk factors for dementia. Thus, a high score on the IQCODE-SR appears to be clinically significant but may indicate risk of depression or dementia and signals a need for further evaluation of these conditions. 


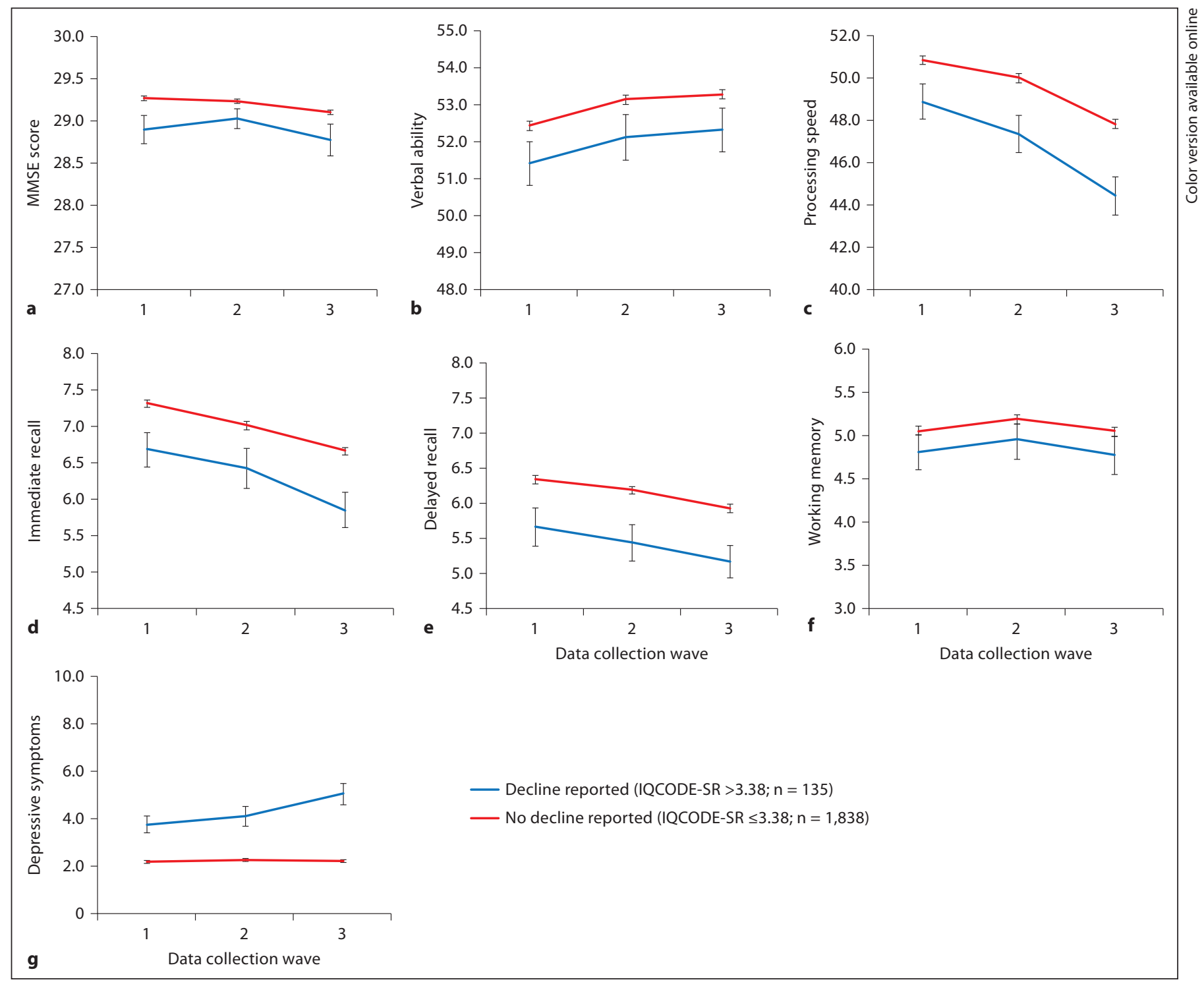

Fig. 2. Longitudinal change in cognition and depression over 8 years as a function of self-reported cognitive decline on the IQCODE-SR (based on pooled estimates of imputed datasets). a Mean MMSE scores. b Verbal ability as measured by mean scores on the Spot-the-Word test. c Processing speed as measured by the number of items completed on the Symbol Digit Modalities Test (oral). d Immediate recall as measured by the number of words recalled on the California Verbal Learning Test. e Delayed recall as measured by the number of words recalled after a delay. $\mathbf{f}$ Working memory based on Digits Backward. $\mathbf{g}$ Depressive symptoms based on the PHQ9 scale. Error bars represent \pm 1 SEM.

\section{Acknowledgements}

This study was supported by the National Health and Medical Research Council of Australia (Grants 973302, 179805, 157125) and National Health and Medical Research Council Fellowships (No. 1002560 to K.J.A., No. 471501 to N.C. and No. 566652 to A.F.J.).

\section{Disclosure Statement}

A.F.J. is the originator of the IQCODE. The other authors have no competing interests to disclose. 


\section{References}

1 Okonkwo OC, Wadley VG, Griffith HR, Belue K, Lanza S, Zamrini EY, Harrell LE, Brockington JC, Clark D, Raman R, Marson DC: Awareness of deficits in financial abilities in patients with mild cognitive impairment: going beyond self-informant discrepancy. Am J Geriatr Psychiatry 2008;16:650-659.

-2 Hanyu H, Sakurai H, Iwamoto T: Are subjective memory complaints mandatory for the diagnosis of mild cognitive impairment? Intern Med 2007;46:791-792.

-3 Slavin MJ, Brodaty H, Kochan NA, Crawford JD, Trollor JN, Draper B, Sachdev PS: Prevalence and predictors of 'subjective cognitive complaints' in the Sydney Memory and Ageing Study. Am J Geriatr Psychiatry 2010;18: 701-710.

-4 Jorm AF, Christensen H, Korten AE, Henderson AS, Jacomb PA, Mackinnon A: Do cognitive complaints either predict future cognitive decline or reflect past cognitive decline? A longitudinal study of an elderly community sample. Psychol Med 1997;27:91-98.

5 Lautenschlager NT, Flicker L, Vasikaran S, Leedman P, Almeida OP: Subjective memory complaints with and without objective memory impairment: relationship with risk factors for dementia. Am J Geriatr Psychiatry 2005;13:731-734.

6 Kliegel M, Zimprich D: Predictors of cognitive complaints in older adults: a mixture regression approach. Eur J Ageing 2005;2:13-23.

7 Graham DP, Kunik ME, Doody R, Snow AL: Self-reported awareness of performance in dementia. Brain Res Cogn Brain Res 2005;25: 144-152.

8 Schmand B, Jonker C, Geerlings MI, Lindeboom J: Subjective memory complaints in the elderly: depressive symptoms and future dementia. Br J Psychiatry 1997;171:373-376.

-9 Geerlings MI, Jonker C, Bouter LM, Adèr HJ, Schmand B: Association between memory complaints and incident Alzheimer's disease in elderly people with normal baseline cognition. Am J Psychiatry 1999;156:531-537.

10 van Oijen M, de Jong FJ, Hofman A, Koudstaal PJ, Breteler MM: Subjective memory complaints, education, and risk of Alzheimer's disease. Alzheimer Dement 2007;3:92-97.

-11 Schofield PW, Marder K, Dooneief G, Jacobs DM, Sano M, Stern Y: Association of subjective memory complaints with subsequent cognitive decline in community-dwelling elderly individuals with baseline cognitive impairment. Am J Psychiatry 1997;154:609-615.

- 12 Gavett R, Dunn JE, Stoddard A, Harty B, Weintraub S: The Cognitive Change in Women study (CCW): informant ratings of cognitive change but not self-ratings are associated with neuropsychological performance over 3 years. Alzheimer Dis Assoc Disord 2011;25:305-311.
13 Smith GE, Petersen RC, Ivnik RJ, Malec JF, Tangalos EG: Subjective memory complaints, psychological distress and longitudinal change in objective memory performance. Psychol Aging 1996;11:272-279.

14 Martin M, Zimprich D: Are changes in cognitive functioning in older adults related to changes in subjective complaints. Exp Aging Res 2003;29:335-352.

15 Dufouil C, Fuhrer R, Alperovitch A: Subjective cognitive complaints and cognitive decline: consequence or predictor? The epidemiology of vascular aging study. J Am Geriatr Soc 2005;53:616-621.

16 Minett TSC, Da Silva RV, Ortiz KZ, Bertolucci PH: Subjective memory complaints in an elderly sample: cross-sectional study. Int J Geriatr Psychiatry 2007;23:49-54.

17 Jungwirth S, Fischer P, Weissgram S, Kirchmeyr W, Bauer P, Tragl KH: Subjective memory complaints and objective memory impairment in the Vienna-Transdanube aging community. J Am Geriatr Soc 2004;52:263-268.

18 Dujardin K, Duhamel A, Delliaux M, Thomas-Antérion C, Destée A, Defebvre L: Cognitive complaints in Parkinson's disease: its relationship with objective cognitive decline. J Neurol 2010;257:79-84.

19 Frerichs RJ, Tuokko HA: Reliable change scores and their relation to perceived change in memory: implications for the diagnosis of mild cognitive impairment. Arch Clin Neuropsychol 2006;21:109-115.

20 Cherbuin N, Jorm AF: The Informant Questionnaire on Cognitive Decline in the Elderly (IQCODE); in Abou-Saleh MT, Katona C, Kumar A (eds): Principles and Practice of Geriatric Psychiatry. Chichester, Wiley \& Sons, 2011, pp 147-151.

21 Cherbuin N, Anstey KJ, Lipnicki DM: Screening for dementia: a review of self- and informant-assessment instruments. Int Psychogeriatr 2008;20:431-458.

22 Jorm AF: A short form of the Informant Questionnaire on Cognitive Decline in the Elderly (IQCODE): development and cross validation. Psychol Med 1994;24:145-153.

23 Jorm AF: The Informant Questionnaire on cognitive decline in the elderly (IQCODE): a review. Int Psychogeriatr 2004;16:275-293.

24 Perroco TR, Damin AE, Frota NA: Short IQCODE as a screening tool for MCI and dementia: preliminary results. Dement Neuropsychol 2008;2:300-304.
25 Jansen APD, van Hout HP, Nijpels G, van Marwijk HW, Gundy C, de Vet HC, Stalman WA: Self-reports on the IQCODE in older adults: a psychometric evaluation. J Geriatr Psychiatry Neurol 2008;21:83-92.

-26 Anstey KJ, Christensen H, Butterworth P, Easteal S, Mackinnon A, Jacomb T, Maxwell $\mathrm{K}$, Rodgers B, Windsor T, Cherbuin N, Jorm AF: Cohort profile: the PATH through life project. Int J Epidemiol 2012;41:951-960.

27 Folstein MF, Robins LN, Helzer JE: The Mini-Mental State Examination. Arch Gen Psychiatry 1983;40:812.

28 Delis DC, Kramer JH, Kaplan E, Ober BA: California Verbal Learning Test. San Antonio, Psychological Corporation/Harcourt Brace Jovanovich, 1987.

29 Baddeley A, Emslie H, Nimmo-Smith I: The Spot-the-Word test: a robust estimate of verbal intelligence based on lexical decision. Br J Psychiatry 1993;32:55-65.

30 Smith A: Symbol Digit Modalities Test (SDMT) Manual. Los Angeles, Western Psychological Services, 1982.

31 Wechsler D: Manual for the Wechsler Adult Intelligence Scale. New York, Psychological Corporation, 1955

- 32 Goldberg D, Bridges K, Duncan-Jones P, Grayson D: Detecting anxiety and depression in general medical settings. BMJ 1988; 297:897-899.

33 Gosling SD, Rentfrow PJ, Swann WB: A very brief measure of the Big-Five personality domains. J Res Pers 2003;37:504-528.

34 Jack CR, Petersen RC, Xu YC: Prediction of AD with MRI-based hippocampal volume in mild cognitive impairment. Neurology 1999; 52:1397-1403.

35 Kral VA: Senescent forgetfulness: benign and malignant. Can Med Assoc J 1962;86: 257-260.

36 Cook T, Bahar H, Sudilovsky A: Age-associated memory impairment: diagnostic criteria and treatment strategies. Int $\mathrm{J}$ Neurol 1987;21-22:73-82.

37 American Psychiatric Association: Diagnostic and Statistical Manual of Mental Disorders (DSM-IV). Washington, APA, 1994.

38 Morris JC: The Clinical Dementia Rating (CDR): current version and scoring rules. Neurology 1993;43:2412-2412.

- 39 Jorm AF, Mather KA, Butterworth P, Anstey KJ, Christensen H, Easteal S: APOE genotype and cognitive functioning in a large age-stratified population sample. Neuropsychology 2007;21:1-8.

-40 Finkel D, Reynolds CA, McArdle JJ, Pedersen NL: Age changes in processing speed as a leading indicator of cognitive aging. Psychol Aging 2007;22:558-568.

41 Schaie KW: Intellectual development in adulthood; in Birren JE, Schaie KW (eds): Handbook of the Psychology of Aging. San Diego, Academic Press, 1996, pp 266-286. 
42 Sikkes SAM, van den Berg MT, Knol DL, de Lange-de Klerk ES, Scheltens P, Uitdehaag $\mathrm{BM}$, Klein M, Pijnenburg YA: How useful is the IQCODE for discriminating between $\mathrm{Al}$ zheimer's disease, mild cognitive impairment and subjective memory complaints? Dement Geriatr Cogn Disord 2010;30:411-416.

43 Lyketsos CG, Lopez O, Jones B: Prevalence of neuropsychiatric symptoms in dementia and mild cognitive impairment: results from the cardiovascular health study. JAMA 2002; 288:1475-1485.
44 Brommelhoff JA, Gatz M, Johansson B: Depression as a risk factor or prodromal feature for dementia? Findings in a populationbased sample of Swedish twins. Psychol Aging 2009;24:373-384.

45 Dik MG, Jonker C, Comijs HC, Bouter LM, Twisk JW, van Kamp GJ, Deeg DJ: Memory complaints and APOE- $\varepsilon 4$ accelerate cognitive decline in cognitively normal elderly. Neurology 2001;57:2217-2222.

46 Laws SM, Clarnette RM, Taddei K, Martins G, Paton A, Hallmayer J, Almeida OP, Groth DM, Gandy SE, Förstl H, Martins RN: APOE- $\varepsilon 4$ and APOE - 491A polymorphisms in individuals with subjective memory loss. Mol Psychiatry 2002;7:768-775.

-47 Striepens N, Scheef L, Wind A, Meiberth D, Popp J, Spottke A, Kölsch H, Wagner M, Jessen F: Interaction effects of subjective memory impairment and APOE4 genotype on episodic memory and hippocampal volume. Psychol Med 2011;41:1997-2006.
48 Small GW, Chen ST, Komo S, Ercoli L, Bookheimer S, Miller K, Lavretsky H, Saxena S, Kaplan A, Dorsey D, Scott WK, Saunders AM, Haines JL, Roses AD, Pericak-Vance MA: Memory self-appraisal in middle-aged and older adults with apolipoprotein E-4 allele. Am J Psychiatry 1999;156:1035-1038.

49 Anstey KJ, Cherbuin N, Christensen $\mathrm{H}$, Burns R, Reglade-Meslin C, Salim A, Kumar R, Jorm AF, Sachdev P: Follow-up of mild cognitive impairment and related disorders over four years in adults in their sixties: the PATH Through Life Study. Dement Geriatr Cogn Disord 2008;26:226-233. 